\title{
Childhood Multilocular Cystic Renal Neoplasm
}

National Cancer Institute

\section{Source}

National Cancer Institute. Childhood Multilocular Cystic Renal Neoplasm. NCI Thesaurus.

Code C6566.

A cystic neoplasm which arises from the kidney and occurs in children. It includes the cystic partially differentiated nephroblastoma and cases in which nephroblastomatous elements are not present. 